\title{
FAKTOR-FAKTOR YANG BERHUBUNGAN DENGAN PELAYANAN PETUGAS PENDAFTARAN RAWAT J ALAN TERHADAP PELAYANAN PRIMA DI RUMAH SAKIT UMUM DAERAH PETALA BUMI PROVINSI RIAUTAHUN 2016
}

\author{
${ }^{1} \mathrm{H}$ enny M aria Ulfa, ${ }^{2}$ Azlina \\ Dosen Program Studi D III RM IK STIK es Hang Tuah Pekanbaru ${ }^{1,2}$ \\ n_hen@ymail.com, azlina7588@gmail.com
}

\begin{abstract}
This research is the related factors with outpatients registration officers service toward service excellence at general hospital Petala Bumi Riau Province. This Research methods using quantitative observational with cross sectional design, Population this research is outpatients patient at RSUD Petala Bumi Riau Province with sample 130 respondents with non-probabi lity sampling techni que, Processing data using test chi square with uni variat analysis and bivariat. The results of the study obtained that there was a correlation between factors the ability, attitude, attention, the act of and responsibilities with service excellence and factors that there was no contact with service excellence that is factors appearance.
\end{abstract}

Keywords : outpatients registration officers service toward service excellence

\begin{abstract}
Abstrak
Penelitian ini bertujuanuntukmengetahuifaktor-faktor yang berhubungan dengan pelayanan petugas pendaftaran rawat jalan terhadap pelayanan prima di RSUD Petala Bumi Provinsi Riau. Jenispenelitiani niadalah kuantitatif observasional desain penelitian cross sectional. Populasi penelitian ini pasien rawat jalan di RSUD Petala Bumi Provinsi Riau,jumlah sampel 130 responden dengan teknik pengambilan sampel non-probabi lity sampling.Anal isis data menggunakan uji Chi square. Hasil penel itian di peroleh bahwa ada hubungan antarafaktor kemampuan, sikap, perhatian, tindakan dan tanggung jawab dengan pelayanan prima dan faktor yang tidak ada hubungan dengan pelayanan prima yai tu faktor penampilan.
\end{abstract}

Kata K unci: Pelayanan Petugas Pendaftaran RawatJ al an, Pelayanan Prima

\section{PE NDAHUL UAN}

Dalam memberikan pelayanan kepada masyarakat rumah sakit tidak hanya di tuntut untuk melengkapi fasilitas pelayanan medis dan sumber daya yang ahli pada bidangnya seperti dokter, perawat dan bi dan tetapi juga harus memiliki fasi litas pendukung lainnya yang harus dapat diandal kan. Fasilitas pendukung seperti rekam medis.

Instal asi rekam medis mempunyai hubungan koordinatif dengan instalasi lain seperti instalasi rawat jalan, instalasi rawat inap, instalasi gawat darurat, serta instalasi penunjang medis yang berkaitan dengan pelaksanaan kegiatan rekammedis di rumah sakit. Tatacara peneriman pasien yang akan berobat ke poli klinik ataupun yang akan dirawat adal ah bagian dari sistem prosedur pel ayanan rumah sakit. Dapat dikatakan bahwa disinilah pelayanan pertama kali yang diterima oleh seorang pasien tiba dirumah sakit, maka tidaklah berlebihan bila dikatakan bahwa di dalamtata cara penerimaan inilah seorang pasien mendapatkan kesan baik ataupun tidak baik dari pelayanan suatu rumah sakit. Tata cara melayani pasien dapat dinilai baik bilamana dilaksanakan oleh petugas dengan si kap yang ramah, sopan, tertib dan penuhi tanggung jawab (Depkes $\mathrm{RI}$, 2006).

Akan tetapi suatu kenyataan pada saat ini masih banyak keluhan masyarakat keluarga pasien dan pasiennya sendiri terhadap kualitas pelayanan yang diberikan oleh pihak rumah sakit. Sering didengar dan dibaca di media cetak berbagai keluhan tentang sikap, pel ayanan dan tindakan yang kurang simpatik, seperti sikap dan ekspresi yang galak dan judes baik terhadap pasien maupun keluarga pasien, kurangnya perhatian yang di berikan terhadap pasien, 
kurang proaktif, apatis dan lamban serta kurang memadai dalammenjalankan tugas di Rumah Sakit.

Dalam rumah sakit salah satu tantangan terbesar adalah menciptakan dan mempertahankan pelangggan yang puas dan loyal . Riset menunjukkan bahwa mempertahankan pelanggan jauh lebih murah dibandingkan merebut pelanggan baru, hal ini mendorong rumah sakit untuk meningkatkan pelayanan petugas agar pasien merasa puas dengan pelayanan yang di berikankepadamereka(Marknesis, 2009).

Menurut Wirts et al dalam Riski Asriani Putri (2015) petugas yang berhadapan langsung dengan masyarakat saat memberikan pelayanan merupakan sumber utama dal ammelaksanakan pelayanan prima, untuk itu petugas perlu mendapatkan perhatian khusus. Hal tersebut dikarenakan sebagian besar penyebab ketidakpuasan pelanggan terhadap pelayanan kesehatan adalah perilaku petugas dalam memberikan pelayanan.

Menurut Wirdaningsih,dkk dalam azmi (2015) Pelayanan prima adalah memberikan pelayanan kepada semua orang, khususnya kepada pelanggan dengan perilaku dan sikap yang baik. Pelayanan prima tidak cukup hanya dengan memberikan rasa puas dan perhatian terhadap pelanggan saja, tetapi juga bagaimana cara merespon keinginan pelanggan sehingga dapat menimbulkan kesan positif pelanggan.

Menurut barata dalam Riski Asriani Putri (2015) bahwa untuk dapat memberikan pelayanan prima (servis excellence) petugas harus memperhatikan beberapa pokok yaitu kemampuan (ability), sikap (attitude), penampilan (appearance), perhatian (attention), tindakan (action) dan tanggung jawab (accountability).

Rumah Sakit Umum Daerah Petala Bumi Provinsi Riau beralamat di JIn. Dr. Soetomo No. 65 Pekanban. RSUD Petala Bumi Provinsi Riau adalah rumah sakit Kelas C milik Pemerintah Provinsi Riau dan merupakan Rumah Sakit rujukan tingkat pertama untuk Kota Pekanbaru. Pada tahun 2011 RSUD PetalaBumi Provinsi Riau ditetapkan sebagai Rumah SakitKelas C melalui Keputusan Menteri Kesehatan Republik Indonesia. No. HK.03.05/I/8000/2010 Tentang Penetapan Kelas Rumah Sakit Umum Petal a BumiProvinsi Riau dengan tugas dan fungsi mencakup upaya pelayanan kesehatan perorangan, pusat rujukan serta merupakan tempat pendidikan Institusi Pendidikan Kesehatan. Berdasarkan data yang diambil di Rumah Sakit Umum Daerah Petala
Bumi Provinsi Riaujumlah kunjungan pasien rawat jalan di RSUD Petala Bumi Provinsi Riau dapat dilihat sebagai berikut.

Tabel 1. K unjungan pasien rawat jalan di RSUD Petala Bumi Provinsi Riau Tahun 2013-2015

\begin{tabular}{llll}
\hline Tahun & $\begin{array}{l}\text { Kunjungan per } \\
\text { Tahun }\end{array}$ & $\begin{array}{l}\text { Kunjungan Per } \\
\text { Bulan }\end{array}$ & $\begin{array}{l}\text { Kunjungan Per } \\
\text { Hari }\end{array}$ \\
\hline 2013 & 45.332 & 3778 & 125 \\
2014 & 35.779 & 2982 & 99 \\
2015 & 34.941 & 2912 & 97 \\
\hline Total & 116.042 & 9672 & 321 \\
\hline
\end{tabular}

Sumber: Laporan RSUD Petala Bumi Provinsi Riau tahun 2013-2015

Berdasarkan tabel 1 diatas dapat diketahui jumlah kunjungan pasien rawat jalan di RSUD Petala Bumi Provinsi Riau pada tahun 2013 kunjungan pasien rawat jalan berjumlah 45.332 kunjungan, di tahun 2014 jumlah kunjungan pasien rawat jalan menurun menjadi 35.779kunjungan, dan di tahun 2015 jumlah kunjungan pasien rawatjal an menurun lagi menjadi 34.941 kunjungan. Dapat diketahui ratarata kunjugan pasien per bulan di tahun 2013 berjumlah 3778 kunjungan, tahun 2014 ratarata 2982 kunjungan, tahun 2015 ratarata 2912 kunjungan.

Berdasarkan survei awal yang dilakukan kepada 10 pasien yang berkunjung di RSUD Petala Bumi Provinsi Riau, 6 diantaranya mengatakan masih kurang puas dengan pelayanan yang diberikan petugas yang kurang senyum, ramah sehingga bisa dikatakan tidak adanilai tambah kedal am pelayanan tersebut dan 4 diantaranya mengatakan cukup puas dengan pelayanan yang di berikan petugas di rawat jalan.

Selain dari suvei terhadap 10 orang pasien yang di lakukan di pendaftaran pasien rawat jalan tentang kepuasan pelayanan di pendaftaranjuga di dapatkan waktu tunggu di pendaftaran rawatjal an rata-rata 20 menit untuk pasien lama dan untuk pasien baru ratarata 15 menit. Sedangkan menurutDepkes RI waktu tunggu untuk pasien lama selama 7 menit sedangkan pasien baru selama 10 menit.

Hal ini dikarenakan kurangnya petugas RekamMedis di Rumah SakitUmumDaerah PetalaBumi Provinsi Riau yang membuat petugas harus merangkap tugasnya. Selain melayani pendaftaran pasien rawat jalan petugas juga melaksanakan tugasnya untuk mengambil berkas rekam medis (Retrive), hal ini yang menyebabkan pelayanan menjadi lama dan kepuasan pasien tidak tercapai dengan maksimal. 
Tabel 2. Tenaga Instalasi R ekam Medis di R SUD Pertala BumiProvinsi Riau Tahun 2016

\begin{tabular}{llll}
\hline No & $\begin{array}{l}\text { Pembagian } \\
\text { Tugas }\end{array}$ & Pendidikan & Status \\
\hline 1 & Ka. Instal asi & $\begin{array}{l}\text { D3 Rekam Medis } \\
\text { S1 Kesehatan Masyarakat }\end{array}$ & PNS \\
\hline 2 & $\begin{array}{l}\text { Pengel ola Data dan } \\
\text { Pelaporan }\end{array}$ & D3 Rekam Medis & PNS \\
\hline 3 & Input Data & SLTA & PNS \\
\hline 4 & $\begin{array}{l}\text { PenyimpananV } \\
\text { Filling }\end{array}$ & D3 Rekam Medis & Kontrak \\
\hline 5 & Koding RI, RJ, IGD & D3 Rekam Medis & Kontrak \\
\hline 6 & $\begin{array}{l}\text { Assembling, Indexing } \\
\text { \& Analising }\end{array}$ & D3 RekamMedis & Kontrak \\
\hline 7 & $\begin{array}{l}\text { Pendftaran Loket 1 } \\
\text { Shif (Pagi\&Sore) }\end{array}$ & S1KesehatanMasyarakat & THL \\
\hline 8 & $\begin{array}{l}\text { Pendaftaran Loket 2 } \\
\text { Shif (Pagi\&Sore) }\end{array}$ & D3 Kebidanan & THL \\
& $\begin{array}{l}\text { Pendaftaran Loket 2 } \\
\text { Shif (Pagi\&Sore) }\end{array}$ & SLTA & \\
\hline 10 & $\begin{array}{l}\text { PenyimpananV } \\
\text { Filling }\end{array}$ & SLTA & THL \\
\hline 11 & $\begin{array}{l}\text { Pendftaran Loket 1 } \\
\text { Shif (Pagi\&Sore) }\end{array}$ & SLTA & THL \\
\hline
\end{tabular}

Sumber: Laporan RSUD Petala Bumi Provinsi Riau tahun 2015

Berdasarkan Tabel diatas dapat diketahui jumlah tenaga rekam medis yang hanya berjumlah 11 orang, yaitu 4 orang tamatan D3 Rekam Medis, 2 orang tamatan S1 Kesehatan Masyarakat, 1 orang tamatan D3 Kebidanan, dan sisanya tamatan SLTA. Untuk bagian pendaftaran hanya ada 2 orang untuk satu shif begitu juga untuk bagian filling hanya ada 1 orang untuk satu shif. Sehingga petugas bekerja tidak fokus dalam satu bagian saja karena jika bagian filling lama untuk mencari berkasnya akan di bantu langsung oleh petugas pendaftaran dan menyebabkan pelayanan menjadi lama.

\section{METODE PENELITIAN}

J enis penelitian yang digunakan kuantitatif observasional dengan menggunakan desain penelitian cross sectional atau studi potong lintang, dimana proses pengambilan data dilakukan dalam waktu yang bersamaan antara variabel bebas dan variabel terikat Penelitianini dilaksanakandi tempat pendaftaran pasien rawatjalan Rumah Sakit Umum Daerah Petal a Bumi Provinsi Riau pada bul anA pril s/d Mei tahun 2016. populasi pada penelitian ini adalah seluruh Pasien rawat jalan di Rumah Sakit umum Petala Bumi Provinsi Riau sebanyak 34.941 pasien. Sampel dalam penelitian ini, hanya akan diambil sebagian dari yang berobatjal an bai k pasien lama maupun pasien baru di Rumah Sakit Umum Daerah Petala Bumi Provinsi Riau tahun 2016 dengan kriteria:

1. Kriteria Inklusi
a. Pasien berobat jalan baru dan lama
b. Pasien yang pandai tul is dan baca
c. 17 tahun ke atas
d. Bersedia mengisi kuisioner

2. Kriteria Ekslusi

a. Pasien yang tidak bisa tulis dan baca

b. Menolak mengisi kuesioner

Pengambilansampel padapenelitianini menggunakan cara non-probability sampling, ditentukan dengan secara purposis.Variabel dalampenelitian ini adalah kemampuan, si kap, penampilan, perhatian, tindakan dan tanggung jawab (variabel independen) dan variabel pelayanan prima (variabel dependen).

Tabel 3. Variabel Penelitian dan Definisi Operasional

\begin{tabular}{|c|c|c|c|c|}
\hline Variabel penelitian & Definisi Operasional & Alat Ukur & SkalaUkur & Hasil Ukur \\
\hline \multicolumn{5}{|l|}{ Dependen } \\
\hline Pelayanan Prima & $\begin{array}{l}\text { Pelayanan yang di berikan kepada pasien } \\
\text { dengan perilaku dan sikap yang baik }\end{array}$ & Kuesioner & Ordinal & $\begin{array}{l}\text { Pelayanan prima }<\text { median } \\
\text { Tidak prima } \geq \text { median }\end{array}$ \\
\hline \multicolumn{5}{|l|}{ Independen } \\
\hline Kemampuan & $\begin{array}{l}\text { Pengetahuan dan keterampilan tertentu } \\
\text { yang mutlak di perlukan petugas untuk } \\
\text { menunjang pelayanan. }\end{array}$ & Kuesioner & Ordinal & $\begin{array}{l}\text { Baik }>\text { median } \\
\text { Kurang baik } \geq \text { median }\end{array}$ \\
\hline Sikap & $\begin{array}{l}\text { Perilaku petugas PPRJ dal am memberikan } \\
\text { pelayanan kepada pasien }\end{array}$ & Kuesioner & Ordinal & $\begin{array}{l}\text { Baik }<\text { median } \\
\text { Kurang baik } \geq \text { median }\end{array}$ \\
\hline Penampilan & $\begin{array}{l}\text { Gaya petugas, baik yang bersifat maupun } \\
\text { dan non-fisik yang mampu merefleksikan } \\
\text { kepercayaan diri dan kredibilitas dari } \\
\text { pihak lain }\end{array}$ & Kuesioner & Ordinal & $\begin{array}{l}\text { Baik < median } \\
\text { Kurang baik } \geq \text { median }\end{array}$ \\
\hline Perhatian & $\begin{array}{l}\text { Bentuk pelayanan petugas PPRJ dengan } \\
\text { mencurahkankonsentrasi untuk lebihfokus } \\
\text { terhadap pasien yang di hadapi }\end{array}$ & Kuesioner & Ordinal & $\begin{array}{l}\text { Baik }<\text { median } \\
\text { Kurang baik } \geq \text { median }\end{array}$ \\
\hline
\end{tabular}


J urnal Manajemen I nformasi Kesehatan Indonesia Vol . 4 No.2 Oktober 2016

ISSN: 2337-6007 (online); 2337-585X (Printed)

\begin{tabular}{lll} 
Lanjutan tabel 3 & & \\
\hline Tindakan & $\begin{array}{l}\text { Suatu cara atau perbuatan nyata petugas Kuesioner Ordinal } \\
\text { PPRJ yang dilakukan untuk meyakinkan } \\
\text { pasien datang kembali }\end{array}$ & $\begin{array}{l}\text { Baik }<\text { median } \\
\text { Kurang baik } \geq \text { median }\end{array}$ \\
\hline Tanggung jawab & $\begin{array}{l}\text { sikap keberpihakan petugas kepada Kuesioner Ordinal } \\
\text { pelanggan sebagai wujud kepedulian } \\
\text { untuk menghindarkan atau meminimalkan } \\
\text { kerugian atau ketidakpuasan pelanggan }\end{array}$ & Baik < median \\
\end{tabular}

jenis data primer, data sekunder dan cara pengambilan data dengan cara membagikan kuesioner kepada responden. Data diolah dengan cara editing, entri data, coding, processing, cleaning sesuai dengan karakteristik dankategori data, kemudian dimasukkan ke dalam computer dengan menggunakan uji Chi square dengan anal isa Univariat dan Bivariat.

\section{HASIL}

\section{Distribusi Karakteristik Responden}

Dalam penelitian ini dapat digambarkan secara umumkarakteristik responden rawatjalan di Rumah Sakit Umum Daerah Petala Bumi Provinsi Riau Tahun 2016 menurut kelompok umur, jenis kelamin dan tingkat pendidikan.

Tabel 4. Distribusi Frekuensi Karakteristik Responden Pasien Rawat J alan di R umah Sakit Umum Daerah Petala B umi Provinsi Riau Tahun 2016

\begin{tabular}{|c|c|c|c|c|}
\hline & $\begin{array}{l}\text { Karekteristik } \\
\text { Responden }\end{array}$ & Frekuensi & Persentase & Total \\
\hline \multirow[t]{2}{*}{1} & Umur Pasien & & & \\
\hline & $\begin{array}{l}<20 \text { Tahun } \\
20-30 \text { Tahun } \\
>31 \text { Tahun }\end{array}$ & $\begin{array}{l}1 \\
48 \\
81\end{array}$ & $\begin{array}{l}8 \\
36,9 \\
62,3\end{array}$ & 100 \\
\hline \multirow[t]{2}{*}{2} & Jenis Kelamin & & & \\
\hline & $\begin{array}{l}\text { Laki- Laki } \\
\text { Perempuan }\end{array}$ & $\begin{array}{l}43 \\
87 \\
\end{array}$ & $\begin{array}{l}33,1 \\
66,9 \\
\end{array}$ & 100 \\
\hline 3 & \multicolumn{3}{|c|}{ Pendidikan Terakhir } & \multirow[b]{2}{*}{100} \\
\hline & $\begin{array}{l}\text { SD } \\
\text { SMP } \\
\text { SMA } \\
\text { SMK } \\
\text { D3 } \\
\text { S1 }\end{array}$ & $\begin{array}{l}1 \\
9 \\
64 \\
5 \\
10 \\
41\end{array}$ & $\begin{array}{l}8 \\
6,9 \\
49,2 \\
3,8 \\
7,7 \\
31,5\end{array}$ & \\
\hline
\end{tabular}

Sumber : Hasil SPSS

Dari tabel 4 di atas dapat dilihat bahwa:

1. Distribusi frekuensi responden berdasarkan umur pasien rawat jalan Rumah Sakit Umum Daerah Petala Bumi Provinsi Riau tahun 2016 diketahui bahwa 1 responden (8\%) berumur lebi h kecil dari 20 tahun, 48 responden (36,9\%) berumur 20 - 30 tahun dan 81 responden (62,3\%) berumur lebih besar dari 31 tahun.

2. Distribusi frekuensi responden berdasarkanjenis kelamin pasien rawat jalan RumahSakitUmum Daerah Petala Bumi Provinsi Riau tahun 2016 diketahui bahwa 43 responden(33,1\%)berjenis kelamin laki-laki dan 87 responden (66,9\%) berjenis kelamin perempuan.

3. Distribusi frekuensi responden berdasarkan tingkat pendidikan pasien rawat jalan Rumah SakitUmumDaerahPetalaBumi Provinsi Riau tahun 2016 yang paling banyak adalah SMA/ sederajatyaitu 64 responden (49,2\%) dan untuk tingkatS1 sebanyak 41 responden (31,5\%). Hal ini menunjukkan bahwa sebagian responden mempunyai pengetahuan yang cukup, dan semakin tinggi pendi dikan seseorang makazkan semakin kritis.

\section{a. Distribusi Variabel Independen}

Tabel 5. Distribusi Responden Berdasarkan Kemampuan, Penampilan, Sikap, Perhatian, tindakan dantanggung jawab Pelayanan Petugas Pendaftaran Rawat di RSUD Petala Bumi Provinsi Riau 2016.

\begin{tabular}{|c|c|c|c|c|}
\hline No & Variabel Independen & Frekuensi & $\begin{array}{l}\text { Persentase } \\
\text { (\%) }\end{array}$ & Total \\
\hline \multirow[t]{3}{*}{1} & Kemampuan & & & \multirow{3}{*}{100} \\
\hline & Kurang Baik & 71 & 54,6 & \\
\hline & Baik & 59 & 45,4 & \\
\hline \multirow[t]{3}{*}{2} & Penampilan & & & \\
\hline & Kurang Baik & 79 & 60,8 & \multirow{2}{*}{100} \\
\hline & Baik & 51 & 39,2 & \\
\hline \multirow[t]{3}{*}{3} & Sikap & & & \multirow{3}{*}{100} \\
\hline & Kurang Baik & 75 & 57,7 & \\
\hline & Baik & 55 & 42,3 & \\
\hline \multirow[t]{3}{*}{4} & Perhatian & & & \\
\hline & Kurang Baik & 71 & 54,6 & \multirow{2}{*}{100} \\
\hline & Baik & 59 & 45,4 & \\
\hline \multirow[t]{3}{*}{5} & Tindakan & & & \multirow{3}{*}{100} \\
\hline & Kurang Baik & 89 & 68,5 & \\
\hline & Baik & 41 & 31,5 & \\
\hline \multirow[t]{3}{*}{6} & Tanggung J awab & & & \\
\hline & Kurang Baik & 88 & 67,7 & \multirow{2}{*}{100} \\
\hline & Baik & 42 & 32,3 & \\
\hline
\end{tabular}


Henny Maria Ulfa dan Azlina. Faktor-Faktor yang Berhubungan dengan Pelayanan Petugas ....

Dari tabel 5 di atas dapat dilihat bahwa:

1. Distribusi frekuensi respondenberdasarkan faktor kemampuan pelayanan petugas pendaftaran rawat jalan Rumah Sakit UmumDaerah Petala Bumi Provinsi Riau tahun 2016 di ketahui bahwa 71 responden (54,6\%) menyatakan kurang baik dan 59 responden $(45,4 \%)$ menyatakan baik.

2. Distribusi frekuensi responden berdasarkan faktor penampilan pelayanan petugas pendaftaran rawat jalan Rumah Sakit UmumDaerah PetalaBumi Provinsi Riau tahun 2016 di ketahui bahwa 79 responden $(60,8 \%)$ menyatakan kurang baik dan 51 responden (39,2\%) menyatakan baik.

3. Distribusi frekuensi responden berdasarkan faktor sikap pelayanan petugas pendaftaran rawat jalan Rumah Sakit Umum Daerah Petala Bumi Provinsi Riau tahun 2016 diketahui bahwa 75 responden $(57,7 \%)$ menyatakan kurang baik dan 51 responden $(42,3 \%)$ menyatakan baik.

4. Distribusi frekuensi responden berdasarkan faktor perhatian pelayanan petugas pendaftaran rawat jalan Rumah Sakit UmumDaerah Petala Bumi Provinsi Riau tahun 2016 di ketahui bahwa 71 responden (54,6\%) menyatakan kurang baik dan 59 responden $(45,4 \%)$ menyatakan baik

5. Distribusi frekuensi responden berdasarkan faktor Tindakan pelayanan petugas pendaftaran rawat jalan Rumah Sakit UmumDaerah Petala Bumi Provinsi Riau tahun 2016 di ketahui bahwa 89 responden (68,5\%) menyatakan kurang baik dan 41 responden (31,5\%) menyatakan baik.

6. Distribusi frekuensi responden berdasarkan faktor tanggung jawab pelayanan petugas pendaftaran rawat jalan Rumah Sakit UmumDaerah PetalaBumi Provinsi Riau tahun 2016 di ketahui bahwa 88 responden $(67,7 \%)$ menyatakan kurang baik dan 42 responden (32,3\%) menyatakan baik.

\section{b. Distribusi Variabel Dependen}

Tabel 6. Distribusi Responden Berdasarkan Pelayanan Prima PetugasPendaftaran Rawat di RSUD Petala Bumi Provinsi Riau Tahun 2016

\begin{tabular}{llll}
\hline No & Pelayanan Prima & Frekuensi & Persentase (\%) \\
\hline 1 & Tidak Prima & 84 & 64,6 \\
2 & Prima & 46 & 35,4 \\
\hline Total & 130 & 100 \\
\hline Sumber : Hasil SPSS & &
\end{tabular}

Sumber : Hasil SPSS

Dari tabel 6 distribusi frekuensi responden berdasarkan pelayanan primapetugas pendaftaran rawatjalan Rumah Sakit Umum Daerah Petala Bumi Provinsi Riau tahun 2016 diketahui bahwa 84 responden $(64,6 \%)$ menyatakan tidak prima dan 46 responden (35,4\%) menyatakan prima.

\section{Analisis Bivariat}

Untuk mendapatkan gambaran hubungan dua variabel antara variabel independen (Kemampuan, Penampilan, Sikap, Perhatian, Tindakan, Tanggung Jawab) dengan variabel dependen (Pelayanan Prima), maka dilakukan analisis bivariat dengan menggunakan uji statistic Chi Square yang dapat dilihat pada tabel berikut ini :

Tabel 7. Hasil Analisis H ubungan K emampuan, Penampilan, Sikap, Perhatian, Tindakan, Tanggung J awab Petugas Pendaftaran Rawat J alan dengan Pelayanan Prima di R umah Sakit Umum Daerah Petala Bumi Provinsi Riau Tahun 2106

\begin{tabular}{|c|c|c|c|c|c|c|c|c|}
\hline \multirow[b]{3}{*}{ Kemampuan } & \multicolumn{4}{|c|}{ Pelayanan Prima } & \multirow{2}{*}{\multicolumn{2}{|c|}{ Total }} & \multirow{3}{*}{$\begin{array}{l}\mathrm{P} \\
\text { Value }\end{array}$} & \multirow{3}{*}{$\begin{array}{l}\text { Odds Ratio } \\
(95 \% \mathrm{Cl})\end{array}$} \\
\hline & \multicolumn{2}{|c|}{$\begin{array}{l}\text { Tidak } \\
\text { Prima } \\
\end{array}$} & \multicolumn{2}{|c|}{ Prima } & & & & \\
\hline & $\mathrm{n}$ & $\%$ & $\mathrm{n}$ & $\%$ & $\mathrm{~N}$ & $\%$ & & \\
\hline Kurang Baik & 56 & 78,9 & 15 & 21,1 & 71 & 100 & \multirow{2}{*}{0,001} & 4,133 \\
\hline Baik & 28 & 47,5 & 31 & 52,5 & 59 & 100 & & $(1,923-8,886)$ \\
\hline \multicolumn{9}{|l|}{ Penampilan } \\
\hline Kurang Baik & 53 & 67,1 & 26 & 32,9 & 79 & 100 & \multirow{2}{*}{0,585} & 1,315 \\
\hline Baik & 31 & 60,8 & 20 & 39,2 & 51 & 100 & & $0,632-2,735)$ \\
\hline \multicolumn{9}{|l|}{ Sikap } \\
\hline Kurang Baik & 57 & 76,0 & 18 & 24,0 & 75 & 100 & \multirow{2}{*}{0,003} & 3,284 \\
\hline Baik & 27 & 49,1 & 28 & 50,9 & 55 & 100 & & $(1,554-6,942)$ \\
\hline \multicolumn{9}{|l|}{ Perhatian } \\
\hline Kurang Baik & 58 & 81,7 & 13 & 18,3 & 71 & 100 & \multirow{2}{*}{0,001} & 5,663 \\
\hline Baik & 26 & 44,1 & 33 & 55,9 & 59 & 100 & & $(2,567-12,491)$ \\
\hline
\end{tabular}


J urnal Manajemen I nformasi Kesehatan I ndonesia Vol . 4 No.2 Oktober 2016

ISSN: 2337-6007 (online); 2337-585X (Printed)

\begin{tabular}{lllllllll} 
Kurang Baik & 63 & 70,8 & 26 & 29,2 & 89 & 100 & 0,049 & 2,308 \\
Baik & 21 & 51,2 & 20 & 48,8 & 41 & 100 & & $(1,075-4,954)$ \\
\hline Tanggung Jawab & & & & & & & & \\
Kurang Baik & 65 & 73,9 & 23 & 26,1 & 88 & 100 & 0,003 & 3,421 \\
Baik & 19 & 45,2 & 23 & 54,8 & 42 & 100 & & $(1,582-7,400)$ \\
\hline
\end{tabular}

Sumber: Hasil SPSS

Dari tabel 7 di atas dapat dilihat bahwa:

1. Hasil analisis hubungan antara kemampuan petugas pendaftaran rawat jal an dengan pelayanan prima, diperoleh bahwa sebanyak 56 (78,9\%) dari 71 (54,6\%) responden yang menyatakan kemampuan petugas pendaftaran rawat jalan kurang baik sehingga pelayanan tidak prima. Sedangkan diantara responden yang menyatakan kemampuan petugas pendaftaran rawatjalan baik ada 28 (47,5\%) dari 59 (45,4\%) responden yang menyatakan pelayanan tidak prima.

Hasil uji Chi Square di dapat $p$ Value $=0,001$ lebih kecil dari $\alpha=0,05$ yang berarti terdapat hubungan antarakemampuan petugas pelayanan pendaftaran rawatjal an dengan pelayanan prima di Rumah Sakit Umum Daerah Petala Bumi Provinsi Riau Tahun 2016.

2. Hasil analisis hubungan antara penampilan petugas pendaftaran rawat jalan dengan pelayanan prima, diperoleh bahwa sebanyak $53(67,1 \%)$ dari $79(60,8 \%)$ responden yang menyatakan penampilan petugas pendaftaran rawat jalan kurang baik sehingga pelayanan tidak prima. Sedangkan diantara respondenyang menyatakan penampilan petugas pendaftaran rawatjal an baik ada 31 (60,8\%) dari 51 (39,2\%) responden yang menyatakan pelayanan tidak prima.

Hasil uji Chi Square di dapat $p$ Value $=0,585$ lebih besar dari $\alpha=0,05$ yang berarti tidak terdapat hubungan antara penampilan petugas pelayanan pendaftaran rawat jalan dengan pelayanan primadi Rumah SakitUmumDaerah Petala Bumi Provinsi Riau Tahun 2016.

3. Hasil analisis hubungan antara sikap petugas pendaftaran rawat jalan dengan pelayanan prima, diperoleh bahwa sebanyak 57 (76,0\%) dari 75 (57,5\%) responden yang menyatakan sikap petugas pendaftaran rawat jalan kurang baik sehingga pel ayanantidak prima. Sedangkan diantara responden yang menyatakan sikap petugas pendaftaran rawat jalan baik ada $27(49,1 \%)$ dari 55 (42,3\%) responden yang menyatakan pelayanan tidak prima.

Hasil uji Chi Square di dapat $p$ Value $=0,003$ lebih kecil dari $\alpha=0,05$ yang berarti terdapat hubungan antara sikap petugas pelayanan pendaftaran rawatjal an dengan pel ayanan prima di Rumah Sakit Umum Daerah Petala Bumi Provinsi Riau Tahun 2016.

4. Hasil analisishubunganantara perhatian petugas pendaftaran rawat jalan dengan pelayanan prima, diperoleh bahwa sebanyak 58 (81,7\%) dari 71 (54,6\%) responden yang menyatakan perhatian petugas pendaftaran rawat jalan kurang baik sehingga pelayanan tidak prima. Sedangkan diantara responden yang menyatakan perhatian petugas pendaftaran rawatjalan baik ada $26(44,1 \%)$ dari $59(45,4 \%)$ respondenyang menyatakan pelayanan tidak prima

Hasil uji Chi Square di dapat $p$ Value $=0,001$ lebih kecil dari $\alpha=0,05$ yang berarti terdapat hubungan antara perhatian petugas pelayanan pendaftaran rawatjal an dengan pel ayanan prima di Rumah Sakit Umum Daerah Petala Bumi Provinsi Riau Tahun 2016.

5. Hasil analisis hubungan antaratindakan petugas pendaftaran rawat jalan dengan pelayanan prima, diperoleh bahwa sebanyak 63 (70,8\%) dari 89 (68,5\%) responden yang menyatakan tindakan petugas pendaftaran rawat jalan kurang baik sehingga pelayanan tidak prima. Sedangkan diantara responden yang menyatakan tindakan petugas pendaftaran rawat jalan baik ada 21 (51,2\%) dari 41(31,5\%) responden yang menyatakan pelayanan tidak prima

Hasil uji Chi Square di dapat $p$ Value $=0,049$ lebih kecil dari $\alpha=0,05$ yang berarti terdapat hubungan antara tindakan petugas pelayanan pendaftaran rawatjal an dengan pel ayanan prima di Rumah Sakit Umum Daerah Petala Bumi Provinsi Riau Tahun 2016.

6. Hasil analisis hubungan antara tanggung jawab petugas pendaftaran rawatjalan dengan pelayanan prima, diperoleh bahwa sebanyak $65(73,9 \%)$ dari $88(67,7 \%)$ responden yang menyatakan tanggung jawab petugas pendaftaran rawat jalan kurang baik sehingga pelayanan tidak prima. Sedangkan diantara responden yang menyatakan tanggung jawab petugas pendaftaran rawat jalan baik ada $19(45,2 \%)$ dari 42 (32,3\%) responden yang menyatakan pelayanan tidak prima 
Hasil uji Chi Square di dapat $p$ Value $=0,003$ lebih kecil dari $\alpha=0,05$ yang berarti terdapat hubungan antara tanggung jawab petugas pelayanan pendaftaran rawat jalan dengan pelayanan prima di Rumah Sakit Umum Daerah Petala Bumi Provinsi Riau Tahun 2016.

\section{PEMBAHASAN}

a Hubungan K emampuan PetugasPendaftaran R awat J alan Dengan Pelayanan Prima

Berdasarkan penelitian yang dilakukan oleh peneliti terhadap 130 responden dan diproses melalui uji Chi Square diketahui bahwa terdapat hubungan antara kemampuan petugas pelayanan pendaftaran rawat jalan dengan pelayanan primadi RumahSakitUmumDaerah PetalaBumi Provinsi RiauTahun 2016. Hal ini dapat di lihat dari hasil uji statistik Chi Square menunjukkan $p$ Value $=0,001$ lebih kecil dari $\alpha=0,05$.

Menurut barata dalam Asriani Putri (2015), Kemampuan adal ah pengetahuan dan keterampilan tertentu yang mutlak di perlukan untuk menunjang program layanan prima, yang meliputi kemampuan dalambidang kerja yang ditekuni, melaksanakan komunikasi yang efektif, mengembangkan motivasi dan public relation sebagai instrumen dalam membina hubungan ke dalam dan keluar organisasi.

Seorang pegawai harus bekejadengan sungguhsungguh beserta segenap kemampuan yang dimiliki ditunjang oleh sarana dan prasarana yang ada. Jika seorang pegawai bekerja dengan setengah hati maka pekerjaan yang dihasilkan tidaklah semaksimal yang diharapkan. Artinya bahwa kemampuan seseorang bisa diukur dari tingkat keterampilan dan pengetahuan yang dimiliki dalam melaksanakan tugas yang dibebankan.

Menurut Hackman dan Oldham dalam Rizki Asriani ragam keahlian merupakan suatu tingkat pekerjaan yang memerlukan berbagai keahlian agar dapat melaksanzkan pekerjaan, mel ibatkan sejuml ah ragam keahl ian dan bakat dari seseorang. Ketika pekerjaan mengharuskan pagawai untuk melakukan kegiatan yang menantang atau menambah keterampilan atau kemampuan, maka pegawai hampir selalu mengalami bahwa pekerjaan mereka berarti. Semakin banyak keahlianyang hanus digunakan, makaakan semakin berarti/bermakna pekerjaan tersebut bagi pegawai yang mengerjakannya.

Menurut peneliti, kemampuan petugas pendaftaran rawat jalan dapat mempengaruhi pelayanan prima karena pendaftaran rawat jalanitu sendiri sangaterathubungannya dengan kepuasan pasien, dimana kepuasan mampu memberikan dasar yang baik bagi pembelian ulang dan terciptanya loyalitas pelanggan, sertamembentuk suatu rekomendasi dari mulut kemul ut yang menguntungkan. Jadi dal am hal ini diharapkan kepada petugas pendaftaran rawat jal an untuk selal u mengetahui informasiinformasi tentang perkembangan rumah sakit dan dokter serta menjaga komunikasi yang baik dengan pasien.

b. H ubungan Penampilan Petugas Pendaftaran R awat J alan Dengan Pelayanan Prima

Berdasarkan penelitian yang dilakukan oleh peneliti terhadap 130 responden dan diproses melalui uji Chi Square diketahui bahwa tidak terdapat hubungan antara penampilan petugas pelayanan pendaftaran rawat jalan dengan pelayanan primadi Rumah SakitUmumDaerah PetalaBumi Provinsi RiauTahun 2016. Hal ini dapat di lihat dari hasil uji statistik Chi Square menunjukkan $\mathrm{p}$ Value $=0,585$ lebih besar dari $\alpha=0,05$.

Menurut barata dalam Asriani Putri (2015) Penampilan adalah penampilan seseorang baik yang bersifat fisik maupun non fisik, yang mampu merefleksikan kepercayaan diri dan kredi bilitas dari pihak lain..

Menurut peneliti, penampilan petugas pendaftaran rawat jalan yang baik dapat mempengaruhi kual itas pelayanan kesehatan. Kepuasan pasien ditentukan oleh adanya hubungan interpersonal dengan petugas dan informasi yang diberikan. Kepuasan pasien terhadap penampilan petugas tersebut menyebabkan pasien kembali lagi ke rumah sakit dan merekomendasikan kepada orang Iain. Jadi dalam hal ini petugas pendaftaran rawat jal an di harapkan untuk memperhatikan keserasian dan keindahan dalam berbusana.

c. Hubungan Sikap Petugas Pendaftaran R awat J alan Dengan Pelayanan Prima

Berdasarkan penelitian yang dilakukan oleh peneliti terhadap 130 responden dan diproses melalui uji Chi Squaredi ketahui bahwaterdapat 
hubungan antara sikap petugas pelayanan pendaftaran rawat jalan dengan pelayanan prima di Rumah Sakit Umum Daerah Petala Bumi Provinsi Riau Tahun 2016. Hal ini dapat di lihat dari hasil uji statistik Chi Square menunjukkan $\mathrm{p}$ Value $=0,003$ lebih kecil dari $\alpha=0,05$.

Menurut teori barata sikap adalah perilaku atau perangai yang harus di tonjolkan ketika menghadapi pelanggan, seperti berpikiran positif dan menghargai orang lain.

Menurut Daryanto, dkk, 2014 Sikap mencerminkan perilaku atau gerak gerik yang terlihat pada di ri seseorang ketikaia menghadapi suatu situasi tertentu atau ketika ia berhadapan dengan orang lain.

Sikapjugabisadimaknai sebagai suatu keadaan dalam diri manusia yang menggerakkannya untuk berbuat dalam aktivitas sosial dengan perasaan tertentu, juga dalammenanggapi objek situasi atau kondisi di sekitarnya. Sikapmembuat seseorang bisadinilai secara positif atau negatif, sekaligus bisa mendapatkan beragam respon dari orang sekitar dan lingkungannya terhadap situasi tertentu.

Menurut peneliti, sikap petugas pendaftaran rawat jalan dapat mempengaruhi pelayanan prima karena pendaftaran rawat jalan itu sendiri sangat erat hubungannya dengan kepuasan pasien, dimana kepuasan mampu memberikan dasar yang baik bagi pembelian ulang dan terciptanya loyal itas pelanggan, serta membentuk suatu rekomendasi dari mulut kemulut yang menguntungkan. J adi dalam hal ini petugas pendaftaran rawatjalan di harapkan untuk memberikan senyum, sapa dan salam saat pasien mendaftar agar dapat memberikan kesan pertama yang baik, petugas pendaftaran juga diharapkan untuk mengi kuti pelatihan tentang kepribadian agar petugas lebih bisa menjaga kesopanan padasaat bekerjadan dapat mengetahui hal-hal apa saja yang di anggap kurang sopan dalam berinteraksi dengan orang lain.

d. H ubungan Perhatian Petugas Pendaftaran Rawat J alan Dengan Pelayanan Prima

Berdasarkan penelitian yang dilakukan oleh peneliti terhadap 130 responden dan diproses melalui uji Chi Squarediketahui bahwa terdapat hubungan antara perhatian petugas pelayanan pendaftaran rawatjal an dengan pel ayanan prima di Rumah Sakit Umum Daerah Petala Bumi Provinsi RiauTahun 2016. Hal ini dapat di lihat dari hasil uji statistik Chi Square menunjukkan pValue $=0,001$ lebih kecil dari $\alpha=0,05$.

Menurut barata dalam Asriani Putri (2015), Perhatian adalah Kepedulian penuh terhadap pelanggan baik yang berkaitan dengan perhatian akan kebutuhan dan keinginan pelanggan maupun pemahaman atas saran dan kritiknya.

MenurutDaryanto, dkk, 2014 konsep pelayanan prima berdasarkan perhatian (Attention) adalah suatu bentuk yang lebih nyata dari perwujudan sikap pelayanan yang anda berikan. Perhatian merupakan bentuk pelayanan dengan mencurahkan konsentrasi untuk lebih fokus terhadap pelanggan yang anda hadapi. Dengan demikian pelanggan akan merasa bahagia merekamemang berada pada tempat yang tepat.

Menurut peneliti, perhatian petugas pendaftaran rawat jalan dapat mempengaruhi pelayanan prima karena pendaftaran rawat jalan itu sendiri sangat erat hubungannya dengan kepuasan pasien, dal ammemberikan pelayanan kepada pelanggan, seorang petugas pada jasa pelayanan harus senantiasa memperhatikan dan mencermati keinginan pelanggan. Apabila pelanggan sudah menunjukkan minat untuk membeli jasa yang kita tawarkan, segera saja layani pelanggantersebutdantawarkan bantuan, sehingga pelanggan merasa puas dan terpenuhi keingginannya. Jadi dalam hal ini petugas di harapkan lebih bersikap aktif terhadap apa saja informasi yang dibutuhkan pasien.

e. Hubungan Tindakan Petugas Pendaftaran R awat J alan Dengan Pelayanan Prima

Berdasarkan penelitian yang dilakukan oleh peneliti terhadap 130 responden dan diproses melalui uji Chi Squarediketahui bahwaterdapat hubungan antara tindakan petugas pelayanan pendaftaran rawatjalan dengan pelayanan prima di Rumah Sakit Umum Daerah Petala Bumi Provinsi RiauTahun 2016. Hal ini dapat di lihat dari hasil uji statistik Chi Square menunjukkan $p$ Value $=0,049$ lebih kecil dari $\alpha=0,05$.

Menurut Daryanto, dkk, 2014 Pelayanan prima dengan konsep tindakan adalah bentuk konkret dari segal a bentuk pelayanan sebelumnya. Pelayanan prima dengan konsep tindakan yaitu suatu cara atau rangkaian perbuatan nyata yang 
dilakukan untuk meyakinkan dan memberikan jaminan kepada pelanggan agar mereka tertarik dan akhirnya membeli atau menggunakan barang atau jasa yang ditawarkan.

Menunut peneliti, tindakan petugas pendaftaran rawat jalan dapat mempengaruhi pelayanan primakarena pendaftaran rawatjalanitusendiri sangat erat hubungannya dengan kepuasan pasien, karena tindakan yang meliputi petugas harus mencatat keluhan pasien di formulir, petugas memberikan informasi dengan jelas dan lengkap kepada pasien, petugas selalu memberikan sal am kepada pasien yang datang dan petugas mengucapkan terima kasih pada akhir pelayanan merupakan tindakan yang sangat diharapkan oleh pasien yang bisa membuat mereka merasa puas. Jadi dalam hal ini petugas pendaftaran rawatjalan di harapkan untuk sel al u cepat dan tanggap dalammel akukan pekerjaan dan memberikan informasi yangjelas kepada pelanggan atau pasien.

\section{f. Hubungan Tanggung J awab Petugas Pendaftaran RawatJ alan Dengan Pelayanan Prima}

Berdasarkan penelitian yang dilakukan oleh peneliti terhadap 130 responden dan diproses melalui uji Chi Square diketahui bahwaterdapat hubungan antara penampilan petugas pelayanan pendaftaran rawatjalan dengan pelayanan prima di Rumah Sakit Umum Daerah Petala Bumi Provinsi RiauTahun 2016. Hal ini dapat di lihat dari hasil uji statistik Chi Square menunjukkan $p$ Value $=0,003$ lebih kecil dari $\alpha=0,05$.

Tanggungjawabadalahsuatusikapkeberpihakan kepada pelanggan sebagai wujud kepedulian untuk menghindarkan atau meminimalkan kerugian.

Menurut peneliti, tanggung jawab petugas pendaftaran rawat jalan dapat mempengaruhi pelayanan prima karena pendaftaran rawat jalan itu sendiri sangat erat hubungannya dengan kepuasan pasien, karena Tanggung jawab merupakan kewaj iban untuk menjalankan tugas dengan baik, Hal ini berarti tanggung jawab merupakan kewajiban atau beban yang harus di pi kul atau di penuhi sebagai akibat dari perbuatan pihak yang berbuat. J adi dalam hal ini petugas pendaftaran rawat jalan di harapkan bertanggung jawab atas pekerjaan dan informasi yang di berikan kepada pasien. Dengan cara selalu mengetahui informasi-informasi terbaru tentang perkemabngan rumah sakit.

\section{SIM PULAN}

Dari penelitian yang telah dilakukan, maka didapatkan hasil sehingga dapat diambil kesimpulan sebagai berikut:

1. Hasil uji Chi Square di dapat $p$ Value $=0,001$ lebih kecil dari $\alpha=0,05$ yang berarti terdapat hubungan antarakemampuan petugas pelayanan pendaftaran rawatjalan dengan pelayanan prima di Rumah Sakit Umum Daerah Petala Bumi Provinsi Riau Tahun 2016.

2. Hasil uji Chi Square di dapat $p$ Value $=0,585$ lebih besar dari $\alpha=0,05$ yang berarti tidak terdapat hubungan antara penampilan petugas pelayanan pendaftaran rawat jalan dengan pelayanan prima di RumahSakitUmumDaerah Petal a Bumi Provinsi Riau Tahun 2016.

3. Hasil uji Chi Square di dapat $p$ Value $=0,003$ lebih kecil dari $\alpha=0,05$ yang berarti terdapat hubungan antara sikap petugas pelayanan pendaftaran rawatjal an dengan pelayanan prima di Rumah Sakit Umum Daerah Petala Bumi Provinsi Riau Tahun 2016.

4. Hasil uji Chi Square di dapat $p$ Value $=0,001$ lebih kecil dari $\alpha=0,05$ yang berarti terdapat hubungan antara perhatian petugas pelayanan pendaftaran rawatjalan dengan pel ayanan prima di Rumah Sakit Umum Daerah Petala Bumi Provinsi Riau Tahun 2016.

5. Hasil uji Chi Square di dapat $p$ Value $=0,049$ lebih kecil dari $\alpha=0,05$ yang berarti terdapat hubungan antara tindakan petugas pelayanan pendaftaran rawatjalan dengan pel ayanan prima di Rumah Sakit Umum Daerah Petala Bumi Provinsi Riau Tahun 2016.

6. Hasil uji Chi Square di dapat $p$ Value $=0,003$ lebih kecil dari $\alpha=0,05$ yang berarti terdapat hubungan antara tanggung jawab petugas pelayanan pendaftaran rawat jalan dengan pelayanan primadi RSUD PetalaBumi Provinsi Riau Tahun 2016. 
J urnal Manajemen I nformasi Kesehatan I ndonesia Vol . 4 No.2 Oktober 2016

ISSN: 2337-6007 (online); 2337-585X (Printed)

\section{DAFTAR PUSTAKA}

Adi sasmito, W. (2007).Sistem Manajemen Lingkungan Rumah Sakit.J akarta: Raja Grafindo Persada

Azmi, (2013). Gambaran Sikap, Perhatian, Tindakan Petugas Tpp Rawat Jalan Dalam Mewujudkan Pelayanan Prima Di Rsud Petala Bumi Pekanbaru Tahun 2015, KTI, STIKes Hang Tuah Pekanbaru

Depkes RI, (2006). Pedoman Penyelenggaraaan dan Prosedur RekamMedi sRumah Sakit. Jakarta: Direktorat Jendral Bina Pelayanan Medik

Daryanto \& Setyobudi, I. (Ed.). (2014). Konsumen dan Pelayanan Prima. Yogyakarta: Gava Media

Febrina,A.R. (2013). Mutu pelayanan kesehatan berdasarkan di ruang rawat inap penyakit dalam.J urnal Administrasi Kesehatan Indonesia Vol.1 No.2 hal 132-134 Surabaya.

Fadillah,Y.N. (2013). Analisis Pengaruh Faktor Pelayanan Prima (Service Excellence) TerhadapKepuasan WajibPajak (Studi Kasus di Kantor Pelayanan Pajak Pratama Malang Utara) vol 1, No 2 hal 206-216 Malang. (http://jirmsi.studentjournal.ub.ac.id/Diakses pada tanggal 16 J uni 2016)

Hasan, Afrizal. (2013). Analisis kepuasan pasien rawat inap ruang flamboyan rumah sakit syafira pekanbaru tahun 2013, Skripsi, STIKes Hang Tuah Pekanbaru
Koentjoro, Tjahjono (2007). Regulasi Kesehatan di Indonesia

Lemeshow, dkk, (1997). Besar Sampel Dalam Penelitian Kesehatan. Gadjah Mada University Press

Marknesis, Tim. (2009). Customer Satisfaction and Beyond. jelajah nusa. Y ogyakarta

Notoatmodjo,S. (2007). Dasar-dasar Kesehatan Masyarakat. J akarta: Rineka Cipta

Putri, Riski Asriani (2015). Faktor-Faktor Yang Berhubungan Dengan Pelayanan Prima Pegawai RawatJ alan Puskesmas Kecamatan Kebon J eruk J akarta Barat Tahun 2015. Skripsi, Universitas Islam Negeri Syarif Hidayatullah.

Sabarguna. (2005). Manajemen Pelayanan Rumah Sakit. Konsorsium Rumah Sakit J ateng.

Soejadi, 1996. Efisiensi Pengelolaan Rumah Sakit. Katiga Bina. J akarta.

Syamsi, I. (2007). Pengambilan Keputusan Dan SistemI nformasi Edisi Kedua, Jakarta: Bumi Aksara.

Thahjono, K (2007). Regulasi Kesehatan di Indonnesia. Yogyakarta : Andi

Wirdaningsih \& Rizal, S. (Ed.). (2011). Modul Melaksanakan Pelayanan Prima. Bandung: Erlangga. 